\title{
Space and Place as User-Experience: Taking Notting Hill as an Example
}

\author{
Pedro Oliveira \\ IPAM Marketing School
}

The articulation between user-experience, design thinking and business anthropology is a promising one and a source of multiple insights yet to be explored. This article is based on an ethnographic account of relations between groups across Notting Hill, West London. It postulates that the building of a fieldwork site can be seen as developmental process of making meaning of place in all ways similar to local meaning-making. Making use of a social psychology method (thematic networks) to analyse fieldwork material the author tries to capture a place that is not ontologically prior to the classifications and counter-classifications played on it. Taking a psychological anthropology stance, it is suggested that place is found in the dynamic contrast of different forms of embodying validity by the human kinds who carry a place and are carried by it, in return. Such a view carries direct implications for the fields of user experience, design planning, urban policies of space and the interaction between business anthropology and usability issues.

\section{INTRODUCTION: PLACE AS FIELD}

"The map is not the territory and the name is not the thing named" (Korzybski, via Bateson, 1979: 27)

In both Ann Jordan's (2002) and Robert Tian, Lillis, and van Marrewijk's (2010) systematisations of business anthropology, design thinking appears as one of the key areas of intersection between corporate ethnography and applied anthropology work. Recent developments in the field of pervasive and ubicomp computing (Dourish and Bell, 2007; 2011) seem to push the notion of space further towards an integrated account of the experience of place, technology usage and implications for interaction design. Despite a growing field of literature in the design ethnography area (Clarke, 2010; Squires, 2002; Wasson, 2000), a stronger articulation is yet to be achieved between anthropological thinking on design, business and corporate anthropologies and the wider issues of space and place that run across all anthropological work concerned with local knowledge. This article is based on an ethnographic account of relations between groups across Notting Hill, West London. It postulates that the building of a fieldwork site can be seen as developmental process of making meaning of place in all ways similar to local meaning-making (Oliveira, 2008). In conceiving of the process as 
developmental, the anthropologist gains a view of place as sheer user experience that can inform processes of urbanization, design planning and public policies of space. Starting from an ethnographic and theoretical explorations of what 'place as learning process means', I will move onto describe the effects that gentrification and subsequent expansion of business has had in Notting Hill, from the people's standpoint. Finally, I will conclude by advancing a series of research lines for business anthropologists interested in issues of urban planning and design thinking, taking Notting Hill as an example.

All anthropological research encompasses a myriad of potential and a particular set of difficulties. This work concerns one year of participant-observation activities from September 2003 to September 2004 in the urban area of Notting Hill (West London), developed as a former member of the Center for Child-Focused Anthropological Research (C-FAR) of Brunel University and sponsored by the Portuguese Foundation for Science and Technology (FCT). To introduce both the difficulties and the potential felt in undertaking fieldwork in Notting Hill, West London, I must start with a short story that happened during my Masters in a London University, two years previous to the beginning of fieldwork.

As a Portuguese student coming from a background in psychology, to move to a multicultural city like London to learn anthropology was a matter of great enthusiasm. It did not take me long to understand that the so called "multiculturalism" of British society did not necessarily encompass the kind of fluid mixing across cultures I had idealized through occasional stays in London. During the first week, the walks across the campus started rendering visible what I would later encounter in fieldwork in Notting Hill: the relatively enclosed groups in which students aligned themselves, on what seemed to me at the time a criterion of ethnic identity, interspersed by occasional mixing across cultures. In the praxis of socializing on campus there was a clear divide, felt by myself and others, between native and non-native speakers. Only many years later did I manage to overcome that divide successfully, thanks to intensive study of the language, elocution classes and ultimately, fieldwork in Notting Hill. Paradoxically or not, the open spaces on campus often struck me as more interesting for the understanding of movements of sociality across-culture than the microcosmos of the pub or other enclosed spaces. This is a feeling I would hold onto for future ethnographic work in Notting Hill.

My Masters class was mixed in all possible ways. We had some newly arrived students like me, some non-native speakers of English, some professional British-natives who had decided to expand their knowledge of anthropology and child development. All in all, we had a vast array of disciplines and backgrounds represented in the classroom with people with an anthropological background actually in the minority. As we were sitting through a kinship lecture, the whole class was told that in order to do some proper anthropology we should dare to leave the UK and pursue our fieldwork abroad. The statement was issued with a total lack of acknowledgment that, as often happens in British post-graduations, at least a third of the class were not British natives, let alone speakers of English as a first language. Some, like me, were new arrivals in the country. At that point I remember raising my hand and stating that as a new arrival in the UK, with English as my second language, life at the moment felt close to a form of fieldwork. I supported my comment with a question: in my case, as a new arrival, would I really have to go abroad to find some "real" anthropological difference? My question was met with some whispering in the class and a monosyllabic comment from the lecturer, who quickly moved on to a different subject. At the end of the class some people complimented me for apparently "giving voice" to what plenty of people had probably felt during the lecture. In asking a question out of genuine 
curiosity, I left the class feeling that my exchange had been interpreted publicly as an affirmation of agency for myself and other non-British participants sitting through that lecture.

Since Bordieu's Outline of a Theory of Practice we have known that power, doxa and classification are inseparable. As Bordieu would put it, perception schemata reify objectivity by producing the misrecognition of the limits of the cognition that make it possible (Bordieu, 1977: 164). To think of limits of cognition inevitably throws up the question of how perception shapes what we observe as real or what we come to form as the constituting elements of a given field. Referring to authors who have challenged the conventional boundaries of what we mean by "the field" in anthropology, Gupta and Anderson suggest that a lack of reflexivity on what "the field" means has served to patrol the boundaries of what we consider real anthropology to be (Gupta and Andersen, 1997: 4). More than an isolated experience, my kinship lecture exchange carries for me a deep symbolic meaning of the liminal experience of being a foreign researcher undertaking fieldwork in a contemporary, urban site of a foreign country. This symbolic meaning has permeated my contacts in the field in multiple ways but ultimately it informs what I felt I could observe in Notting Hill, taking my own position of power into account. This episode mirrors, I will argue, how the constitution of what we call "the field", inside and outside anthropology, is embedded in Bordieu's notion of doxa. Finally, it mirrors something I would find in Notting Hill, over and over again, in trying to understand how different Notting Hillers observe the place they live in.

The more I engaged with Notting Hill the more it became evident that two sets of classifications would have to be taken into account: informants' views of the place they live in and informants' views of how other Notting Hillers, perceived as holding a different position of power, observe the place that emerges to them as real. As one of my pub informants once put it:

"Notting Hill is a mindset. People won't tell you that, but that is what it is...if we're both standing here in the pub" [we are in a rather crowded pub, halfway down Portobello Road; and my informant points to our feet to indicate coincidence of spatial location] "and if I have the money, people see me as someone from Notting Hill. If I don't have the money, I'm from Ladbroke Grove. No one talks about it like this, but that's what it is: a mindset."

Tracing a philosophical history of place, the philosopher Edward Casey mentions how "chaos" in Ancient Greece, Hesiod's work in particular, pointed originally to an idea of emerging order over the fragmentation that "chaos" connotes in modernity (Casey, 1998: 9). In Hesiod, according to Casey, chaos is both emerging order, a place for things to be and a place of separation. In trying to provide an account of Notting Hill deeply rooted in psychological anthropology, I will not start with an approximate, "neutral" objective, the geographical description of the streets my fieldwork is based in, or an historical account based on facticity. I will start, rather, by exposing the classificatory maps found in the field, fueled by particular images of social memory of place, and their possible intersections. In so doing, I will try to show how different Notting Hillers come to embody the validity of a particular place that is simultaneously symbolic, imaginary and real: a place of chaos, separation and emerging order. I will conclude by suggesting that only externally, by an artefact of reason, is place likely to be seen as geographic, objective and concrete, even as a starting point for anthropological description within which "social relations" are contained. 


\section{Fieldwork and Methodology: Reversible Thematic Networks}

There is no equivalent to the field of literary criticism or commentary philosophy in anthropology, Geertz argues, and we are a long way from becoming more reflexive about how ethnographies are put together or how text in anthropology is constructed; according to the author, discussing interpretation in anthropology is altogether a different issue from discussing how an anthropology text, leading to interpretation, is constructed in the first place. If there is plenty of the former discussion in anthropology, there is, proportionally, just as little discussion on the latter (Geertz, 2004).

Inter-subjectivity is always and invariably the key by which we come to embody a set of certainties about the surrounding world built in exchange with others (Toren, 1999: 2-7). This section is an attempt to contribute to Geertz's problem on elucidating the path to text construction and subsequently trace the steps for my interpretation of Notting Hill. I will throw out as a hypothesis, subject to further discussion, that the process by which I have come to embody the validity of this particular place is not substantially different from the developmental process by which people of Notting Hill, old and new to place, come to gradually consolidate in intersubjectivity the experience of a place lived as real. Similarly to Toren, I do not conceive developmental learning processes, of place or other matters, as radically different in adults and children, or radically different in old and new inhabitants of place, but rather assume them to exist in logical continuity (Toren, 1999).

The challenge is therefore to expose the fieldwork methodology herewith used, with a view to both fulfilling Geertz's above-mentioned predicament and describing a process of going from place to space that brings closer together the anthropologist's theoretical discourse and the descriptive commitment (Casey, 1996:15). A professed need to openly discuss methodology and issues of validity as a heritage of my psychology training is one reason, but not the only reason, why I argue this work as a piece of psychological anthropology. The other reason pertains to the isomorphism in "embodying the validity" of a particular field by both anthropologist, gradually building an image of place, and the images of place informants have come to in their processes of building personhood. In exposing the isomorphism between them one may just be answering more than Geert's "how": one may be advancing explanations of cognitive co-construction of place, binding anthropologist and informants together. For all these reasons, to talk method is substantially important.

As a starting point in the field, studying an open area of a British city my first logical priority was to delimit objective boundaries within which I could contain the dispersed networks of relations found in the field. Trying to do fieldwork in an area where thousands of people move on a daily basis by focusing primarily on the open space I often felt that the masses of disparate data I would collect would hardly find any form of unity. Moreover, what different informants reminded me of, at different points in the fieldwork, is that even "a longer network remains local at all points" (Latour, 1993: 117). Wherever I was in Notting Hill, in the company of people who saw themselves as being from Notting Hill as far as research goes, I was still on location.

Examples of ethnograhic work focusing on public spaces seemed different from the kind of description I was looking for and therefore only partially useful as far as ethnomethodology is concerned. For example, in an enthralling ethnography of an open market square ("plaza") in

Cartago, Costa Rica, the anthropologist Setha Low (Low, 2000) combines a rich ethnographic analysis of the historical, political and sociocultural context of the development of two plazas in Costa Rica, with accounts of local meaning, first person narratives, poems and novel excerpts on 
the public space. Low's work is a powerful reflexion on a political and social transformation of public space yet the analytical path by which the different sources involved were put together (Geertz's "how"), as is often the case in ethnography, is left far from clear. Moreover Low's work provided me with two important clues on how to approach place methodologically: to treat an open, public space as a prime object of ethnography similar in all ways to the study of an enclosed context; to address historical production on an open, public place as any other kind of ethnographic data.

A more helpful approach for my purposes, methodology-wise, stems from the work of Joana Passaro (Passaro, 1997). In an article suggestively entitled "You Can't Take the Subway to the Field", Passaro remarks how a process of negotiation between herself and anthropological community in a study of the homeless in open areas of New York, took place right to the end of fieldwork. During this process of negotiation, Passaro was often advised by colleagues to try to circumscribe tighter boundaries in her field (e.g. finding a shelter in which to study the homeless) rather than hanging around with the homeless in public spaces, or taking the subway to the field. Passaro exposes her exchanges with the anthropological community as highly informative of what we tend to conceive as proper fields and "real anthropology" (Passaro, 1997: 152). Rather than surrendering to images of serendipity in encounters with informants, Passaro provides a description of a multi-sited fieldwork site that is accessed differently over distinct fieldwork periods. Here, the anthropologist goes as far as to change her looks in order to interact with informants perceived in different positions of power at different moments in the field. Methodology-wise, from Passaro's work, I took the idea that Notting Hill too could be seen as a multi-sited fieldwork site that could be accessed at different moments, with a view to understanding inter-group relations or how different groups in place perceived one another. Hence, like Passaro, two months into the fieldwork I started taking the underground to Notting Hill with a clear agenda of where and whom to hang around with, sometimes making small adjustments along the way considering the people I was interviewing or spending time with.

I count as my main research points in Notting Hill a local youth center and a community arts center (where I was allowed to take part in some of the musical workshops as preparation for Carnival), a local Evangelical Church, a local pub right in the middle of Portobello Road, a working-class pub off Ladbroke Grove station, two Portuguese-based cafés, a nursing home right off Portobello Road and the local history group, where I attended sessions of the reminiscence and memory groups. More than places for regular hanging around, all these places provided an extension of the original social networks I found in the field and an opening of other places and contexts. Geographically speaking, all the research points are contained within the open area contemplated in this study, the main participant-observation point being the triangle formed by the intersection of Portobello Road, Golborne Road and Ladbroke Grove Tube Station. Over the period of one year, the field was accessed by one of the three tube stations surrounding the area, Westbourne Park, Ladbroke Grove and Notting Hill.

The more I engaged with people about the place they lived in, in pubs, at the local youth center in the community art school, the more I felt that if anything could organize the dispersed information gathered across the many different sites in Notting Hill, an iterative process between data and analysis would have to be defined almost from the outset. As a result of the iterative process an analytical step soon occurred from thinking of Notting Hill as a place inhabited by a group of people to the relations between the different groups of people inhabiting Notting Hill. Relations between groups in an open area of a city, rather than one particular group or context, soon became the object of my ethnography. 
By using the three languages at my disposal (Portuguese, Spanish and English) to engage with informants of different backgrounds in the Notting Hill area, it became gradually apparent that using several languages from the outset was already a powerful form of participant observation. Fieldnotes became multilingual and this brought its own set of challenges. To contain the higher dispersion of data stemming from an urban, multi-sited fieldwork, an iterative process between fieldnotes and theoretical analysis started from a very early stage. This involved taking a weekly time to code notes, classify them and organize them in domains of analysis. Domains were given different colors with notes coded according to color-domain. The original domains subdivided and the relations between them kept changing over the course of fieldwork. At the phase of writing up, notes had built up to a thematic network analysis (Attride-Stirling, 2001). The exception being that my thematic network analysis was of a reversible kind. I will proceed to explain what I mean by a thematic analysis of a reversible kind.

Thematic networks is a method for qualitative analysis developed by social psychologist Attride-Stirling, in order to answer the "how question" in analysis of qualitative material, i.e., how do we get to the analysis we arrive at in the process of making sense of qualitative data. The author states that "thematic analyses can be usefully aided by and presented as thematic networks: web-like illustrations (networks) that summarize the main themes constituting a piece of text" (Attride-Stirling, 2001:386). In pursuing a pictorial representation of the organizing principle of data analysis, thematic networks evolve from the extraction of lower-order premises (the so called "basic themes") to themes that encompass gradual levels of abstraction ("organizing themes") and meta-themes that encompass the inclusion of all material, the latter being called "global themes" (Attride-Stirling, 2001:388). The analytical steps involved in building a thematic network can be broken roughly into three stages: reduction or breakdown of a text, exploration of the text and integration of the exploration. In explaining the principles underlying these three stages, the author subdivides them into six stages, each formed by a few discrete analytical steps (Attride-Stirling, 2001: 391). For the purposes of this article, I will not expound the exposition of the author's six stages and associated sub-steps, but rather trace the differences and similarities between fieldnote analysis and thematic networks:

\title{
TABLE 1 \\ PICTORIAL REPRESENTATION OF A THEMATIC NETWORK VIA ATTRIDE-STIRLING
}

\author{
Basic Theme \\ Organizing Theme - GLOBAL THEME - Organizing Theme
}

\section{Basic Theme}

If Attride-Stirling's method serves as a good candidate to answer Geertz's "how", a difference with anthropology needs to be established from the start (Oliveira, 2010). Thematic networks is a method used when data collection is completely finished and it is mainly an inductive process. My experience of doing ethnography is one where as a function of new material collected for every field visit, there is a constant shift between induction and deduction happening from the outset. Retracing the genealogy of the idea of field in anthropology, Gupta and Anderson refer to the field as "a clearing whose deceptive transparency obscures the 
complex processes that go into constructing it" (Gupta and Anderson, 1997: 5). My "field" was built with an idea in mind of finding out what place meant for the many informants I found across it. Whatever serendipity unfolded in my encounters with informants, this idea remained the ethnographic focus right to the end of fieldwork.

Analysis-wise, my work started in the opposite direction from Attride-Stirling, i.e., by identifying a global theme (meaning of place) and branching out to the different sub-domains that could form it. As new notes were coded and classified along the fieldwork process, domains sub-divided, leading to new basic and organizing themes, shaping the meaning of the global theme in return, in a feedback loop. Drawing from Attride-Stirling, I therefore call my analysis "reversible thematic networks" insofar as the relation between global, organizing and basic themes can be reversed at any point, depending on new data feeding into the process.

I shall proceed with an analytical description of place, obtained through this methodology to finally include an approximate pictorial representation of what a reversible thematic network of Notting Hill looks like. I will suggest that the reversible nature of this thematic network sheds light on how we "learn to learn" about place. More so, I will suggest that it is precisely because humans have the capacity to both learn about things and to learn about the process of learning (what Bateson calls "deutero-learning") that full perceptive chaos is avoided or made meaningful in relation (Bateson via Visser, 2003).

In this paper, as a deliberate rhetorical strategy, I will not make use of individual informants' narratives as a starting point for ethnographic description. Conventional anthropological rhetoric can only apply to some extent to places that are not conventionally anthropological: as Marc Augé relevantly puts it, any attempt to study the open space of an airport poses a whole new set of problems, in terms of theory and methodology (Augé, 2000). As Augé also refers, the starting point of any anthropological place is geometric, that is, made of lines, intersections of lines and points of intersection (Augé, 2000:57). Although there is some spatial coincidence between the lines, intersections and points obtained in anthropological analysis and the lines, points and intersections found in objective geography, that coincidence is far from perfect (Augé, 2000:58).

In tandem with Augé's conception of the anthropological place as point, line and intersection, I will not present an ethnographic description of place that starts out with (or ends with) informants' individual narratives or, for that matter, an account of place that starts out with an objective, geographic, situated description of place to then introduce the informants in it. To do so would be to undermine the whole purpose of an article that tries to radicalize an attempt at proximity between anthropological theory and the anthropologists' descriptive commenting. Hence, informants are not here taken as unique, individual entities but the sources of information that crossed with classifications stemming from other informants, permitting the exposition of a place made predominantly of finite intersection. Neither Notting Hill as a place nor the informants in it are here taken as unique entities but part of a classificatory tissue that can travel along physical place and extend to other geographical areas, while maintaining a core identity. Insofar as place is a local, situated synthesis of class conflicts played in British national identity, the more place travels, I will argue, the more place is likely to remain the same. In that synthesis, classifications and counter-classifications played in it are as material (if not more so) as the physical structure to which these classifications pertain.

As a hypothesis subject to further discussion, I will reiterate the possible parallelism between place as formed by the ethnographer through the thematic networks analysis, place as formed by the people in it through their description of lines, points and intersection and what we can learn from the interplay between them. 


\section{PLACE AS INTERSECTION: CLASSIFYING AND COUNTER-CLASSIFYING}

I must start by clarifying my use of an idea of class in this context. By "class" I am here closer to emic distinctions of perceived social differentiation in Notting Hill than a particular, theoretical, etic school of thought. It is because informants of Notting Hill have self-disclosed to me as people of a professed class identity (mostly working-class), both to explain who they are, as well as to provide me with an insight of the different power positions found in place, that I use the term "class". Hence, class is here taken as a measure of social differentiation stemming directly from informants' self-presentation strategies and meaning-making of place. Analytically, class is here used as a process of making sense of self and social difference. As Beverly Skeggs puts it, how we study class "is also how we learn to know and speak of the social and the self" (Skeggs, 2004: 41). In speaking through and for their self-proclaimed class positions, the people of Notting Hill speak for place, the contrasts found in it, and ultimately themselves.

Notting Hill often appears on London maps as a differentiated area, if not for rigorous historical reasons, certainly for the presence of the Notting Hill Carnival and the international projection gained after the film "Notting Hill". An analysis of geographical material associated with Notting Hill evidences that in a final analysis, the historical origins of the name are largely unknown (Adams and Bartlett, 1993; Gladstone and Barker, 1969; Vague, 1997; Whetlor, 1998; Whetlor and Bartlett, 1996). So are the boundaries of what divides Notting Hill from its adjacent area, Ladbroke Grove (Davies and Anderson, 2001). If some historical sources opt for an unproblematic identification of Ladbroke Grove as the area surrounding the tube station, or unclear differences in postcode, the boundaries between the two areas are better understood in informants accounts, especially when seen as boundaries operating from the present to the past. Carnival and the Notting Hill film have a substantial role in forming these boundaries. As I was

\section{FIGURE 1}

\section{MAP OF NOTTING HILL IN LONDON}

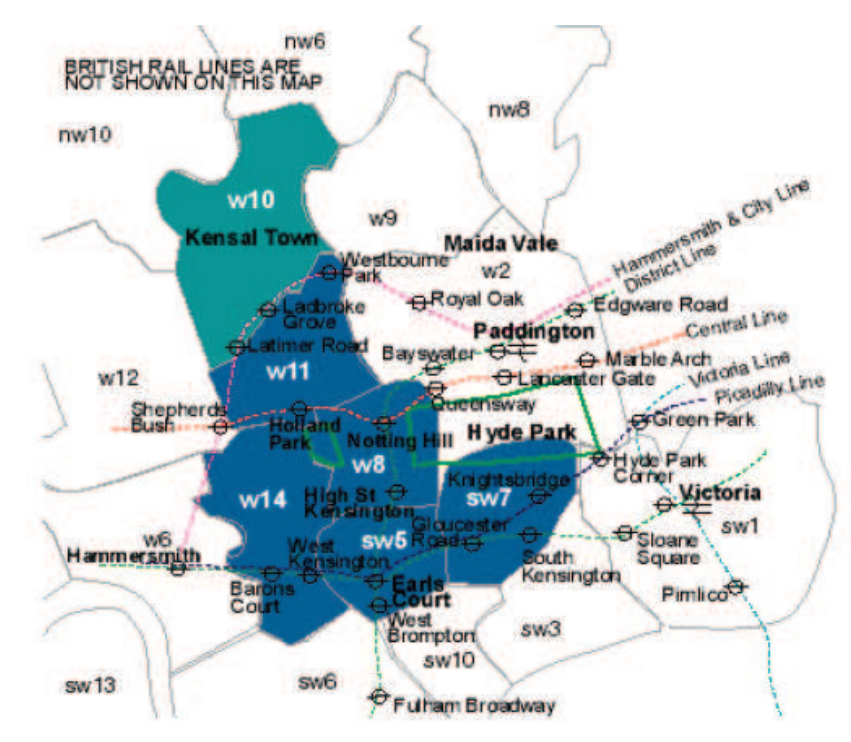


told in the field by people who describe themselves as "locals of Ladbroke Grove", evoking a greater history of occupation of territory allied to a working-class position to justify their claim of locality, the Carnival would better be called "Ladbroke Grove Carnival". Reasons for this will hopefully become clearer as the text unfolds.'

Initially led by members of the Afro-Caribbean group who migrated to the area after the Second World War, the Carnival is one of the largest street festivals known in Europe. The Carnival often mirrors the expression of a duality between unleashed celebration of diversity and concerns related to public health and safety. Every year, there is some press release on the safety measures that will be implemented before Carnival and ongoing discussion as to whether the streets of Notting Hill are the right place to hold the Carnival or if the Carnival should be moved elsewhere. As the event is a major source of income for the London economy, discussions about the Carnival, who organizes it and what the hidden economic agendas are, permeate local pub discussion long before the event. To be a real local, it was often explained to me, is to move as far away from the area as possible during Carnival celebrations and take no part in it. Like many things in the area, Carnival is often seen as something that evolved from a small family and community event to a gentrified celebration that no longer mirrors the "real" multiculturalism of Notting Hill.

Gentrification is a process that was clearly accelerated by the "Notting Hill" Hollywood blockbuster, rendering Notting Hill one of the most popular tourist destinations. Notting Hill is a 1999 romantic comedy set in the area, starring Hollywood stars Julia Roberts and Hugh Grant. The screenplay is by Richard Curtis, a screenwriter who used to live just off Portobello Road, and was written with his flat and location in mind. There is no greater insult to locals than tourists who come into one of the local pubs asking for the flat and location of the movie.

An analysis of the abundant historical production on the area, by the Notting Hill local history group, inevitably throws up the question of how social memory works retrospectively. Notting Hill is known for many things: being a fashionable, affluent area, but also one marked by the memory of the race riots that occurred in 1958 between the post-war newly arrived AfroCaribbean populations and the white working classes. The more one moves from local history production on the ethnic histories of migrant populations, to local historical production on place, the more a conflict on occupation of place going from culture to class comes out in historical data. The following passage concerns Portobello Road, one of Notting Hill's central streets and home to its best known street market:

By the end of the century shops were flourishing along the length of Portobello Road catering for the many different classes of people who lived in the streets around (...) In the Portobello Road small family shops and businesses of all kinds began to close, from the early 1960s, unable to compete with the prices the new supermarkets and chain stores could offer. With the arrival of fridges and freezers in homes and increase in car ownership, people had less need to buy daily from small specialist shops. They could get most of their week's needs in a single trip to one of the large supermarkets elsewhere, page 57, Portobello, its history, its past, its present"

In engaging with people of Notting Hill, I realized, time and time again, that there was not one Notting Hill but many areas that could be potentially defined as such. In this classfication, an area historically marked by conflicts of culture (the riots), defining an external image of place 
going from past to present (Carnival as a symbolic inversion of the riots), gives place to an internal image of Notting Hill, going from culture to class, where Notting Hill is equated with gentrification:

It is the beginning of December, 2003, and I am walking around trying to find one of the creative and film industry studios where I was told that "real" Notting Hillers are to be found. The studios are situated in what I understand, geographically-wise, is to be considered Ladbroke Grove or North Kensington. I take a break in a small coffee place opposite the studios. I start a conversation with one of the owners. The owners tell me the studio has been in construction for three years and it is almost finished. I comment it must be good for business to be based opposite a studio. The owner tells me it does not make much of a difference. Their coffee place is not the kind of place people opposite the studios come to. Things were better in the past, when they had warehouses instead of the studio and workers who actually came to the coffee place and kept business going. I ask them if the area the coffee place is situated in is Notting Hill. They answer negatively. Notting Hill is "by the gate" well, it's all down to Notting Hill these days".

Informants are no strangers to understanding that what one calls the area indicates a particular position of power. On the contrary: Notting Hill is a highly power-reactive place and a sense of personhood in Notting Hill is better understood in the degree to which people consciously resist stereotypes associated with a particular identity. An example stems from my conversations with informant N., of Afro-Caribbean descent and director of one of the local arts and community centers:

For N., the area the center is based in is clearly Notting Hill: "Everyone in the Caribbean and around the world knows where Notting Hill is." She goes on to say that "there is an old socialist faction that calls the place Ladbroke Grove, but in reality, it is Notting Hill". Nevertheless, "to understand what people call the place, you have to look into people's powerbase".

As to the center, $\mathrm{N}$ explains, it is not a multicultural center ("that is not our philosophy") but a very "individualistic" arts center. N. has "a particular vision of art" and she has, in her own words, "imposed her views on the structure", even deliberately going against those who want the center to work as a base for the Notting Hill Carnival. "History does not define you, but you have to know about history." If a "black kid" (informant's term) comes in the center wanting to take a particular class, a choice more expected of a "black kid", people in the center start by acquiescing to the request, but "then we take them for a tour around the building" (meaning that the person is shown all the activities offered in the center, before a final choice is made).

Unlike N's account of place, my exchanges with the young people of Notting Hill bring to light that a place called "The Grove" exists far beyond an old socialist faction. To be let in on "the Grove" is to be let in on a local idiom of what place "really" stands for. In the local idiom of pubs and the youth centers, The Grove sets apart the tourist who comes to place looking for the 
Notting Hill house where the film was shot and the people who really belong to place in each other's eyes. Often, when meeting new people in the pub, I was advised to stop calling the place Ladbroke Grove and address it simply as The Grove so that I would not betray my nonbelonging to place.

Belonging to place, from a Grove standpoint, involves both belonging from a working-class position and the capacity to successfully identify and relate to others who belong to place from a similar, self-professed, working-class position. The Grove is both a symbolic border of separation between perceived class status in place and, by and large, a border of separation between the outside and the inside, authenticity and fake place. In local history production, "The Grove" is also a synonym of the counter-culture from the sixties and seventies emerging in the area, the so-called bohemian life of Notting Hill and more recently an object of artistic and hiphop musical production by new generations. When the young generations produce work about "The Grove", place is addressed as dangerous, socially deprived, unsafe and deeply marked by social conflict. An example is found in the following poem called "The Grove, a street near you":

"These streets that I walk down I know them so well

I've lived on these footpaths

And tasted their hell

Behind twitching curtains

And dog soiled paths

A mattress that's dumped

Stained with memories and laughs

And kids wearing hoods

That cover their eyes

Hands in on both pockets

But empty of life"

In an anthropology of suburban London, Southall, the anthropologist Gerd Baumman reflects on how perceived rights of occupation of place follow a logic of historical continuity in which ethnic minorities who have been in place for longer claim rights over ethnic minorities newly arrived to place (Baumman, 1996). "The Grove" is a place where, in youngsters, musical production and lived experience, ethnic and class conflict coalesce. Like Southall, predominant forms of conflict lived by the young are directly dependent on time of occupation of territory. As informant $\mathrm{N}$. once put it:

My father is Trinidadian, but he married an aristocrat. I came from a family of musicians, so I became one." In spite of a mixed background pointed out by $\mathrm{N}$ herself, she stresses that she grew up exposed to all the things people of different backgrounds grew up exposed to. N. points out as an expression of her reservations towards ideas of "ethnicity": "I'm supposed to be a black mother, but it's rubbish".

$\mathrm{N}$. finds that "black" is more a "political identity", than "color or pigmentation". She points out the case of the Serbian/ Eastern European immigrants (i.e. "white", color-wise), new inhabitants of the place, who are suffering abuse from their neighbors. N. sees it as a case of the Eastern European going through what 
"blacks" went through, years ago, when becoming a part of Notting Hill. As to the Moroccan group, according to N., they are living the generational conflict the blacks also went through, years ago.

If any longer network remains local at all points (Latour, 1993) one must strive to understand how class-ridden images of British national identity (e.g. Fox, 2004; Paxman, 1998) are processed and digested at the local level. To understand the conflicts experienced by the young in The Grove they co-exist in, one must understand who is eligible to live in a place predominantly ridden by identitary class-conflict and who can only inhabit a place that is predominantly ridden by ethnic-based identitary conflict. As I confirmed in many of my conversations with the youth center service-users, a multi-ethnic population in their late teens, newly arrived generations to place are yet to be given the status of belonging fully to The Grove, or the place of class-ridden conflict. Rather than forming youth gangs based on an identification to place with working-class, they will form youth gangs that are ethnic-based, often fighting the multi-ethnic gangs built around images of The Grove. All of this co-exists with resistance stemming from Grovers themselves, between the ones who passively fall under a description of being from the Grove and the ones who strive to "better themselves" and escape it, like informant C.:

I go into the youth center, near Ladbroke Grove tube station, for the first time. I have made myself look the Ladbroke Grove way. As usual, the extent to which dress sets my entrance in a new space, I cannot determine. Notwithstanding, one of the social workers of the youth center (P.), on the basis of quick impression, comments that when he first saw me come in, he thought I was a "local kid", there to join the activities.

I am told there are "youth gangs" that frequent the center, one of the gangs, at the time of fieldwork, is in conflict with a gang based in Shepherd's Bush. P. says that part of the job description of a youth worker is to stop an institution like this center becoming associated with a particular gang so that kids should not be made to feel they are entering "someone else's territory" (...).

I start visiting the center on Thursday evenings, for a music workshop. It is a workshop frequented by many youngsters who write songs on "the Grove". Here, I meet informant C. who is seventeen, mixed race, and has lived in the area for a long time, but only recently joined the center.

C. writes songs on "racism". He sees a lot of racism directed towards "white people" these days. Being mixed race he feels he has it harder than many people in the place. C., unlike others, does not write about "the Grove", for in his view when people write about the Grove, they "think they have to go around carrying guns". C., on the contrary, has "never carried no gun". "I never saw the police beat up no-one around here, it's an idea people have in their heads," C. remarks.

Permeating C's description of place runs the idea often found in Notting Hill of place as "mindset". More than a dichotomy based on the lived experience of territory it stretches towards a classificatory tissue of the different kinds of people that populate Notting Hill. From The Grove a consensual image of the people of Notting Hill as a particular human kind or a collection of kinds, emerges. In this divide, people of the Hill are seen as people who predominantly live "in their minds or heads". What follows is an account of the forms of imagination found in 
informants who proclaim themselves people of "The Grove" about the kind of people Notting Hill is made of.

Often called "people of the Hill" they need not inhabit the geographic area where a physical hill exists to be classified as such. People of the Hill can be found anywhere in place as much as people from the Grove. Undoubtedly, the overlapping interpenetration of council estates and private property Notting Hill is known for contributing to this phenomenon. Sharing a ground flat in a two or three storey Victorian house where a single mother living on benefits pays a symbolic rent to a housing trust, co-existing with the media neighbor upstairs who bought their flat outright for over five million, they are not exactly living in the same place. In The Grove idiom, the difference between people from The Grove and people from the Hill comes precisely from the fact that sharing communal gardens, as they might, or buying fruit and veg in Portobello street market, as they do, only Grovers truly know that the two kinds of people (the singlemother on the ground floor and her media type upstairs neighbor) are not co-existing in the same place. This is far from self-evident to people from the Hill who, on the contrary, sometimes openly profess they have moved to Notting Hill drawn by "the edgy" side of place: the bohemian lifestyle, often equated with the excesses that Ladbroke Grove is supposed to contain. Hillers, according to Grovers, do not share the same place. They cannot event start to acknowledge the hardship lived in The Grove because their place is one of a "mindset" or something located "in the head".

In spaces where class conflict is equalised (such as the pub or the Portobello open market) they are able to produce exchanges in a reality lived as similarly different by people of the Hill and substantially different by people of the Grove. Across the board, classification and counterclassification work side by side. In the same way that some Grovers resist the classification of people from the Grove in order to "better themselves", Hillers often resist the classification of posh, stiff-upper-lips or uptight, as they have decided to move to an area with a bit of an "edge" to it. There is nothing more amusing to locals than seeing someone from the Hill, in their twenties or thirties, whose flat was bought by kin, go around the area trying to come up with a fake working-class accent. To be a Grove "local" is also mirrored in this form of knowledge: knowing who is resisting classifications of class position and why they are doing it. So what is Notting Hill, from a Grove standpoint? To understand it, we must carry on exploring "The Grove" images of the kinds of people that inhabit Notting Hill and their perceived differences.

Grovers tend to classify the well-off families new to the area as either French or American, and above all white, feeding a consensual image of new inhabitants of Notting Hill as white and posh. Moreover, they are often referred to as foreigners or people from abroad. As the story goes, if you are a white French or American investment banker, you move into the area, buy a property divided into flats, rebuild it as a single-unit, bring your family in, and finally set up a boutique in Westbourne Park, one of the most expensive areas property-wise, to keep your wife happy. Otherwise, if you are in your mid-twenties/early thirties and able to buy a fancy flat in the area, chances are that you are a trustafarian, that is, someone whose flat has been bought by well-off kin, and who lives off a trust fund set up by that kin.

There are conflicting versions of what constitutes a trustafarian. An obvious pun on the word "Rastafarian", trustafarians need not wear dreadlocks or display any other kind of visible diacritical indicator, to be singled out as such. The most common version is that a trustafarian is a well-off young person (twenties/early thirties) who has traveled half the world on the trust fund set up by their family and then returns to London, deciding to live in a place like Notting Hill for the appeal of its bohemian side equated with working class multiculturalism. As the story goes, 
once in Notting Hill, the trustafarian goes around socializing, consuming cannabis and cocaine, all in all having an easy life. The trustafarian is someone for whom Notting Hill is a lifestyle. Trustafarians are the kind of people who choose to hang around a street like Portobello, in a senseless attempt at resisting the classification associated with privileged family and a privileged class position. "You're not a rasta, you're a trasta" is one of the most offensive insults young people can throw at one another. Stella McCartney, daughter of aging rock star billionaire Paul McCartney and herself a famous British clothes designer and owner of a fashion workshop in Golborne Road, stands as the local epitome of a trustafarian. Trustafarians and foreigners are not just well-off, but generally white, irrespective of their nationalities. From a Grove standpoint, both kinds are examples of people from the Hill. In the long run, their practices of inhabiting place will set them apart from those who actually stand a chance of ever becoming a part of it and those who will inhabit it as an insular universe. Drawn by the local appeal of Notting Hill's communities, once in place trustafarians and foreigners will do their best to stay away from them. Yet to understand this movement, we need to clarify the difference between foreigners and communities.

In conversations and pub encounters with locals, one must always attend to the use of the word foreigner, for what may strike a stranger or newcomer to the area as a symptom of ethnic or racial discrimination (the foreign versus the non-foreign) is actually a form of discrimination based primarily on class difference. Foreigners are, first and foremost, the new white, posh inhabitants of the area. On the other hand, economic immigrants established in the area are communities, or locals or people from the Grove, and only secondarily people with cultures. Hence, the fact that both foreigners and communities hold non-British nationalities does not, necessarily, render them both "foreign". This happens all the more in a place where communities are the object of concern insofar as they are being pushed out of the area by the newcomers - the foreigners of Notting Hill - as a consequence of the increase in property values and gentrification posh foreigners tend to bring with them. Matters are made more diffuse as, I was told, people who might easily be called a trustafarian based on the expensive flat bought by kin just off Portobello Road, would seek an identification with "The Grove" over Notting Hill, and talk of trustafarians as a kind they did not belong to. Trustafarians, like the boundaries of place, are not a fleshed kind of people per se. Like the boundaries of place, a trustafarian is something that contains a form of truth about place that is simultaneously symbolic, imaginary and real.

Things that come from exotic places, Strathern argues, "are always evidence of people's local capacity to draw them in" (Strathern, 1988: 251). Communities are, first and foremost, working-class people and in The Grove what is working-class is not to be singled out as foreign. If we dare to imagine place as a situated synthesis of the class-conflict imagery that permeates Britain as a whole (Evans, 2007) it is possible to describe communities as non-British groups who have been successfully assimilated to place irrespective of nationality because, over history, they have been successfully assimilated into place from the only class position that can render them "real" locals: working-class people. Unlike newly arrived groups of immigrants who can only inhabit place from a position of either invisibility, ethnic identity or both, communities can visibly occupy a place that is made a place through the class-conflict that communities themselves partake in. For example, if someone in the communities manages to get some more money along the way, he will be seen as someone "who did well for himself" but they will not change to the status of foreigner, irrespective of nationality, as that was not the position in place they started out with. Unlike communities, because foreigners come to Notting Hill from a 
privileged class position they can never become truly local or part of a community and even losing their fortune will not grant them that privilege.

In place, keeping a safe distance from communities, foreigners will keep looking for the real edge of Notting Hill or the places communities live in. Urban planning is a direct reflexion of that as the development of the area seems marked by the search for the next "real" thing. At the time of fieldwork, the construction of a closed condominium was about to start North of Harrow Road, which was considered by the planners the place that contained the "edge" Ladbroke Grove had been starting to lose over the past years. Built with the media types of Notting Hill in mind the closed condominium ensures the middle classes a sheltered life in a self-contained unit even including medical services, however surrounded, beyond the gates, by what is promoted as the yet uncontaminated multiculturalism, edge or vibe that even Ladbroke Grove no longer possesses. From an historical point of view this process is far from surprising.

My analysis of informants' histories of different generations evidences that the movement of British natives along this collection of adjacent areas follows a logical path. In the seventies and eighties, generational conflict between those who came to be Notting Hillers happened in Chelsea, with the young generations moving from "posh" Chelsea into Notting Hill, much to their kin's dissatisfaction, to be among the growing artistic community and the promise of an alternative lifestyle. In the eighties, faced with the ever growing gentrification of Notting Hill, those who come to be Ladbroke Grovers moved from Notting Hill to the safely dangerous, adjacent Ladbroke Grove, as an act of rebellion towards kin. As the gentrification in Ladbroke Grove progresses, with property prices increasing, artists moving out to adjacent areas and The Grove itself being swamped by a Notting Hill equated with gentrification, new adjacent areas such as North of Harrow Road, can stand as a contemporary promise of an alternative life style.

Indeed, as I drew from ethnographic material gathered seven years ago a petition was found on Facebook in 2010 to stop Portobello Market being shut down, threatened by ever growing gentrification of the area or stuck in a fight with a Notting Hill that knows no boundaries. Adding onto it, the current London riots of 2011, give us another layer of how class struggles are operating in contemporary London, in Notting Hill and beyond it. Yet in places more defined by the classificatory kinds who populate them than objective, geographical, a priori boundaries, where are people really moving to? To rephrase my question: are people moving at all?

Following Casey, I suggest that only a theoretical position that does not run athwart the anthropologists' descriptive commenting is a good candidate for forming a sketch of an answer (Casey, 1996). I will finish off by exploring that theoretical position and arguing that whatever physical moves happen in Notting Hill and adjacent areas, inasmuch as place precedes space, and inasmuch as Notting Hill is a local synthesis of class-ridden, identitary conflicts that have been part of British identity since time immemorial, the more place moves, the more place stays the same.

\section{CONCLUSION: HUMAN KINDS, USER EXPERIENCE AND BUSINESS ANTHROPOLOGY}

In the methodology section of this paper I suggested that by exposing the thematic networks in terms of basic, organizing and global themes that have drawn me to a particular analysis of Notting Hill, one could get a sense of how developmental aspects of place formation, leading to a place lived as commonly real, are brought to life across the board of informants: 


\section{Basic Themes ------------------Organizing Themes-------Global Theme (Meaning of Place)}

"Self-Proclaimed class-position"

“Grove versus Hill"-------------------Place formation in human kinds

"Experience of The Grove"

“Place as “mindset"--------------------Idealism versus Realism

"Communities versus foreigners"

“Resisting stereotypes"--------------Assimilation versus accommodation/Personhood

As a reversible thematic network, every element can become predominant at a given point in time of learning about place before it reaches a more stable accommodation towards the global theme/meaning of place. By calling it "reversible" I am not implying that having embodied a certain position in place (being from Notting Hill) one can unlearn that position and become someone from Ladbroke Grove, as if by magic. By "reversible" I mean simply that in the trajectory of learning to learn about place, at a given point in time, what was an organizing theme (e.g. Place as "mindset") becomes a basic theme, until a higher-order encompassing theme (idealism versus realism) subsumes it in relation to other basic themes.

In anthropological language, the progression from basic to organizing themes is a progression from emic to etic. In psychological language the crescendo from basic themes to global theme is a crescendo in a process of learning that stems from second-order learning (or "deutero-learning"): learning to learn about one's position in place in ever-constant relation to contrast. Such analysis does not place me above the people I studied and by the end of fieldwork, as a function of my own deutero-learning, I had fully identified with the Grove over Notting Hill and actively opted for places where Grove was more likely to be found. If place is a "mindset", it is as real a mindset as our capacity to embody a certain validity associated with place that ultimately reflects an overlapping connection between self and the social that we come to recognize as part of ourselves. Recognizing it, however, is not a synonym for the capacity for changing it. So, to conclude: if place keeps moving in Notting Hill, where are people moving to?

My concluding hypothesis is that Notting Hill/Ladbroke Grove is the kind of place where a former model of personhood (British identity built upon images of class and class difference) and a contemporary model of personhood (cultural diversity equated with greater equality) come together to form a shared meaning of place that can be reached by all in the field. In learning to learn about place in this particular way, informants transcend cultural difference and become a kind of person through an identification of class expressed in a sense of place (Hill versus Grove). Whether they are physically located in what some would consider the geographic center of Notting Hill, what others would consider the geographic center of Ladbroke Grove, or even in a fancy urbanization North of Harrow Road-where the "real" Ladbroke Grove is now to be found - is less relevant than acknowledging that much as place travels, the kinds that make place and are made by place in return, will travel with it.

Classifications stemming from these kinds do not subsume the uniqueness of each informant or the uniqueness of place and to assume so would be an act of hubris. Nonetheless, they unite 
the newly arrived immigrant in their twenties, the old English pub-goer who has lived in the Grove since time immemorial and the new foreigner in place in a reality where all of them, knowing or not knowing one another personally, work symbiotically in the formation of a particular classificatory matrix. Identifying this matrix allows for an ethnography of a vast, urban, open area, whose limits and human kinds that populate it are both symbolic, imaginary and real. Here, I return to my informant's adagio about the true nature of Notting Hill:

"Notting Hill is a mindset. People won't tell you that, but that is what it is. If we're both standing here in the pub and if I have the money, people see me as someone from Notting Hill. If I don't have the money, I'm from Ladbroke Grove. No one talks about it like this, but that's what it is...a mindset."

When the experience of carrying Ladbroke Grove as a place is taken into account, the idea of a place that starts by being circumscribed by the objective boundaries of a map, only to be populated later, and made meaning of, by the people in it, in a second instance, completely loses ground. Anthropological user-experience does not conform to Cartesian mappings as a starting point to think place. Hence, the idea that a greater interpenetration of private and public housing in Notting Hill necessarily leads to equality is brought down facing an insider's view of what it means to be in place, or out of it. Moreover, in Notting Hill and other places in London, governmental policies of thinking and designing the city still tend to start with statistical, geourban indicators, only to contemplate a cultural view of place in a second instance. Business anthropologists concerned with issues of design thinking have therefore an open gap in ethnographies of place to push their agenda further in many directions:

a) Helping to plan sustainable business. Notting Hill, in the view of its inhabitants, is a place where gentrification has reached to anihilate family run business; a detailed and careful ethnographic assessment of place can help urban policies in designing solutions that allow for a better accomodation of small and medium businesses;

b) Enhancing quality of life. Notting Hill, in the perspective of its inhabitants is a place constructed from the outside, a touristy destination and somewhere that has long lost its authenticy. Business anthropologists concerned with design thinking can push a role forward as applied space ethnographers that help to bring together tourismrelated business with the implementation of space attributes which guarantee greater quality of life for its inhabitants;

c) Managing place's 'brand capital'. Place can be thought of as a brand that needs to find the right balance between current users (fidelization) new users (new 'segments'), brand mission, statement and equity. Ethnography can provide insightful clues on how to promote an experience of authenticy of the brand 'Notting Hill' both for locals and non-locals of place. In the assessment of brand capital, the human kinds that are said to populate a place can be seen as 'personas' that either contribute to an experience of brand's authenticity or otherwise, undermine it, while leading to a dissociation from the experience of place;

d) Assessing unarticulated needs related to place across different social and ethnic groups. If gentrification propels social tension across different social and ethnic groups, there is no absolute guarantee that different groups will present the same unarticulated needs as a response to expansion of business, increase of property prices 
and subsequent inter-ethnic tension. Ethnography across different social and ethnic groups sharing the experience of place can lead to an inventory of needs serving as a guide for urban policies of space and territory;

e) Assessing place as 'trend'. To gain a full, articulated view of place as brand and manage its equity, one needs to assess transformations in its symbolic capital across generations. The ethnographic study here undertaken seems to indicate that across generations place tends to shifts towards the search of a space in it that incorporates the 'working class' and 'multi-cultural' attributes as synonym of brand equity (Ladbroke Grove over Notting Hill). Business anthropologists occupied with place as trend can work side by side with architects and urban planners in antecipating the needs of new generations and designing spaces that meet these needs.

Space ethnography is therefore an area that opens all possibilities for business anthropologists provided that a broader notion of business ethnography is put forward as a means of balancing sustainability with knowledge of place as brand. Future query on the material herewith presented should provide further directions in forging new ways of approaching that balance.

\section{REFERENCES}

Adams and Bartlett (1993). History in Our Bones: Notting Hill Lives Remembered. Kensington and Chelsea History Community Group.

Attride-Stirling, J. (2001).Thematic networks: an analytic tool for qualitative research. Qualitative Research, Vol. 1, No. 3, 385-405.

Augé, M. (1995). Non-places. Introduction to an anthropology of super modernity. Verso books: London / New York.

Bateson, G. (1979). Mind and Nature: A Necessary Unity. Bantam, New York.

Baumann, G. (1996). Contesting Culture: discourses of identity in multi-ethnic London, Cambridge: Cambridge University Press.

Bourdieu, P. (1977). Outline of a Theory of Practice, trans. Richard Nice (Cambridge: Cambridge University Press.

Casey, E (1996). How to get from Space to Place in a Fairly Short Stretch of Time:

Phenomenological Prolegomena in Feld and Basso (eds) Senses of Place. Santa Fe: School of American Press.

Casey, E. (1997). The fate of place. A philosophical history. University of California Press.

Clarke, J. A. (ed). (2010). Design Anthropology: Object Culture in the $21^{\text {st }}$ Century. Springer; 1st Edition. 
Davies and Anderson (2001). Inside Notting Hill. London: Portebello Publishing.

Dourish, P. and Bell, G. (2007). The Infrastructure of Experience and the Experience of Infrastructure: Meaning and Structure in everyday encounters with Space. Environment and Planning B: Planning and Design, 34, 3, 414-430.

Dourish, P. and Bell, G. (2011). Divining a Digital Future: Mess and Mythology in Ubiquitous Computing. Cambridge: MIT Press.

Evans, G. (2007). Educational failure and working class white children in Britain. Palgrave MacMillan.

Ferguson, J. and Gupta, A. (1997). Discipline and practice: "the field" as site, method, and location in anthropology in Ferguson and Gupta (eds). Anthropological Locations: Boundaries and Grounds of a Field Science, California Press.

Fox, K. (2005). Watching the English: the Hidden Rules of English Behaviour. London: Hodder and Stoughton.

Geertz, C. (2004) Interview at DSpace /Cambridge Archives:

http//www.dpace.cam.ac.uk/handle/1810/438

Gladstone and Barker (1969). Notting Hill in bygone days. Clive Bingley: London.

Jordan, A. (2003). Business Anthropology. Prospect Heights, Long Grove, IL:Waveland Press.

Latour, B. (1993). We have never been modern. New York: Harvester Wheatsheaf.

Low, S. (2000). On the plaza: the politics of public space and culture. Texas, Texas University Press.

Marilyn, S. (1992) The Decomposition of an Event. Cultural Anthropology 7, 244-54.

Oliveira, P. (2008) Placing class as a form of culture: implications for anthropology and systemic psychotherapy. In Context, Association for Family Therapy Magazine, pp. 29-31.

Oliveira, P. (2010). Focused ethnography through thematic networks: defining validity in business anthropology research. International Journal of Business Anthropology, North America Press.

Passaro, J. (1997). "You can't take the subway to the field: village epistemologies in the global village" in Ferguson and Gupta (eds)_Anthropological Locations: Boundaries and Grounds of a Field Science, University of California Press.

Paxman, J. (1999). The English: a Portrait of a People. Penguin Books Ltd. 
Setha, L. (2000). On the Plaza: The Politics of Public Space and Culture. Austin: University of Texas Press.

Squires, S. and Bryan, B. (eds). (2002). Creating Breakthrough Ideas: The Collaboration of Anthropologists and Designers in the Product Development Industry. Westport, Connecticut: Bergin and Garve.

Skeggs, B. (2004). Class, self, culture. London: Routledge.

Strathern, M. (1992). The Decomposition of an Event. Cultural Anthropology, Vol. 7, No 2, pp. 244-254.

Tian, R, M. Lillis, and Van Marrewijk, A.H. (2010). General Business Anthropology. Miami, FL: North American Business Press.

Toren, C. (1999). Mind, Materiality and History. Explorations in Fijian Ethnography. London: Routledge.

Vague, T. (1997). Entrance to the Hipp: an Historical and Psychogeographical Report on Notting Hill. Published by Tom Vague (a quite old inhabitant).

Visser, M (2003). Gregory Bateson on Deutero-learning and Double-Bind: a Brief Conceptual History. Journal of History of the Behavioural Sciences, Vol. 39(3), 269-278.

Wasson, C. (2000). "Ethnography in the Field of Design" Human Organizations, Vol. 59, No. 4, 377-389.

Whetlor and Bartlett (1996). Portobello, its people, its past, its present. Published by the Kensington and Chelsea Community History Group.

Whetlor, S. (1998). The Story of Notting Dale: From Potteries and Piggeries to Present times. Published by the Kensington and Chelsea Community History Group.

\section{Addendum:}

Pedro Oliveira, Brunel University (UK)/oliveiraatbrunel@yahoo.co.uk. The author thanks the editors and reviewers of IJBA for their constructive suggestions to revise this paper. 